\title{
Research on local pressure bearing capacity of prestressed deep corbels under interaction of vertical and horizontal loads
}

\author{
YIN Xinsheng ${ }^{1, a}$, LIU Yang ${ }^{1, b}$ \\ ${ }^{1}$ Green Building Technology Engineering Center , Jilin Jianzhu University , Changchun130118 , \\ China \\ ayinxinsheng06@eyou.com, b692844325@qq.com
}

Keywords: prestress, deep corbel, local compression, horizontal ultimate bearing capacity

\begin{abstract}
In order to further improve the stress state of reinforced concrete deep corbel under local loads, study on the influence of prestressing on the horizontal bearing capacity. Through the calculation and analysis on the horizontal ultimate bearing capacity of deep corbel under certain local loads, and then reinforce the deep corbel by the form of external prestressing. According to the calculation results, compared with the normal working state, the crack resistance of deep corbel in prestressed steel strand under the constraint have greatly improved and horizontal ultimate bearing capacity increase obviously. With the increasing of the local loads, the horizontal ultimate bearing capacity of deep corbel is decreasing.
\end{abstract}

\section{Introduction}

Deep reinforced concrete corbel is commonly used for bearing structure of Chinese modern industrial building. Compared with the traditional ordinary corbel, Because of the height of the overhanging area increasing, the bearing capacity of deep corbel is improved largely. But with the increase of the crane tonnage, the horizontal force produced by braking load makes a greater threat on damage of deep corbel.

The model of deep reinforced concrete corbels is established by finite element analysis software ABAQUS. And analyze on the horizontal ultimate bearing capacity under the local load. The extended area of concrete is constrained by external prestressing to improve the crack resistance of concrete in the compression area. And then study on the influence of external prestressing force on the horizontal ultimate bearing capacity.

\section{The establishment of the model}

Brief Introduction of the model. A deep corbel of single storey industrial building, the reinforcement and size as shown in Figure 1 . The concrete strength grade is C40. The protective layer thickness is $40 \mathrm{~mm}$. The deep corbel's width is $400 \mathrm{~mm}$. The HRB400 grade steel bar is used in the concrete. The load area is $200 \times 400 \mathrm{~mm}$ of the rectangular area. The prestressed nominal diameter is $15.2 \mathrm{~mm}$, and the area of prestressed steel strand is $139 \mathrm{~mm}^{2}$. Steel plate size is 200x600mm, thickness of $20 \mathrm{~mm}$.

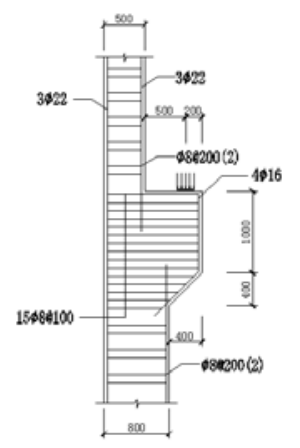

Fig-1 corbel wit rebar 
The establishment of the corbel.In this paper, the finite element software ABAQUS is used to analyze, and then achieve the establishment of the model through the CAE function. Deep corbel, rebar and steel plate are separated to create. Using three-dimensional solid element to establish deep corbel and steel plate, rebar by 3D line unit, specific material properties are shown in table 1 . The concrete damage model is used for concrete and prestress the steel strand by cooling method. The prestressed steel strand and steel plate are tied by MPC constraint to reinforce the deep corbel. The vertical load applied in the load area is $20 \mathrm{MPa}$, and then apply $100 \mathrm{kN}$ in the horizontal direction. The displacement of up and bottom surfaces are constrained in three directions. Unit size is $0.15 \mathrm{~m}$. Because this paper mainly discusses the stress state of the deep corbel during working, establishing the middle part to analyze.

Tab.1 form of material properties

\begin{tabular}{ccccc}
\hline & $\begin{array}{c}\text { Elastic } \\
\text { modulus } \\
\left(\mathrm{N} / \mathrm{mm}^{2}\right)\end{array}$ & Poisson's ratio & $\begin{array}{c}\text { Yield strength } \\
(\mathrm{MPa})\end{array}$ & $\begin{array}{c}\text { Linear } \\
\text { expansion } \\
\text { coefficient }\end{array}$ \\
\hline Concrete & 32500 & 0.2 & & \\
\hline Steel plate & 210000 & 0.3 & & $1.2 \times 10^{-5}$ \\
\hline Steel & 200000 & 0.3 & 400 & \\
\hline Steel strand & 200000 & 0.3 & 1860 & \\
\hline
\end{tabular}

Calculation results and analysis.The corbel and the reinforcement according to conventional calculation can meet the requirements of specification. In order to explore the effect made by the form of external prestressing on horizontal ultimate bearing capacity of deep corbel, calculate and analyze on the deep corbel of reinforced concrete. And then comparative analysis on the condition of the deep corbel constrained by external prestressing, obtain the increased range of the horizontal bearing capacity. Compared The ultimate horizontal bearing capacity of different vertical loads.

\section{Analysis of horizontal ultimate bearing capacity under normal working condition}

The calculation results are shown in the following figure. When the horizontal load is applied to the $50.471 \mathrm{kN}$, the deep corbel is destroyed. Combined with Figure 2 and Figure 4 it can be seen that deep corbel in the interaction of vertical load and horizontal load, crack first in the upper column and the platform appear. With the horizontal load increasing, cracks gradually to the inclined overhang of lower part to carry out, and ultimately cross through deep corbel overhanging region, leading to the failure. In Figure 2 you can see, the rebar of crack region were tensile yield, indicating that after the cracking of concrete, the rebar began to enter into the work state. When

the cracks cross through the extended area, the rebar are ultimately all the tension yield, and the deep corbel is destroyed at last. The tensile force of concrete in middle part of the deep corbel is larger. There is a "pull stress zone"in the middle part and the direction of it is the same to that of crack development.

According to figure 3, Figure 6 and Figure 7 can be seen deep corbel under vertical load, compressive stress along the loading area passed to extended area slope, formed an obvious pressure "stress zone" "[1], which is the same to the working state of deep corbel only under the vertical load. Through the "stress zone", the load will be gradually transferred to the bottom of the corbel. The position of the maximum compressive stress is located in the intersection of bottom part and the inclined plane. Under the influence of the local pressure in the loading area, the compressive strength of the bar is lost and the concrete is crushed. 

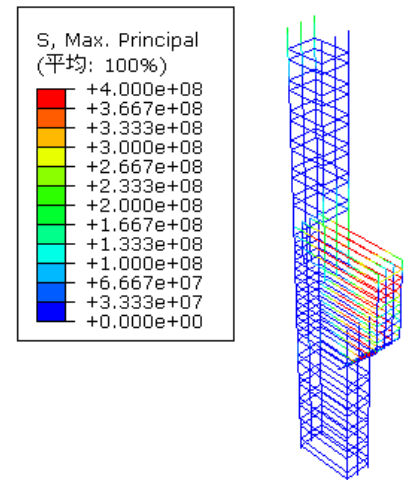

Fig-2 The first principal stress nephogram of rebar
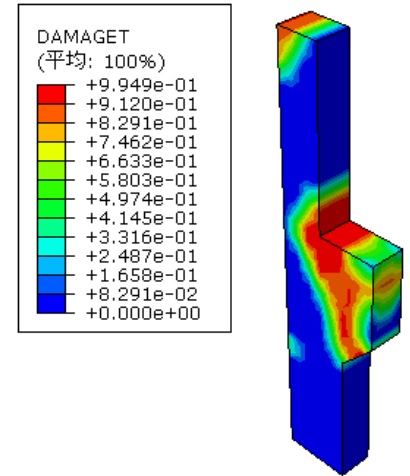

Fig-4 Tensile damage nephogram of deep corbel
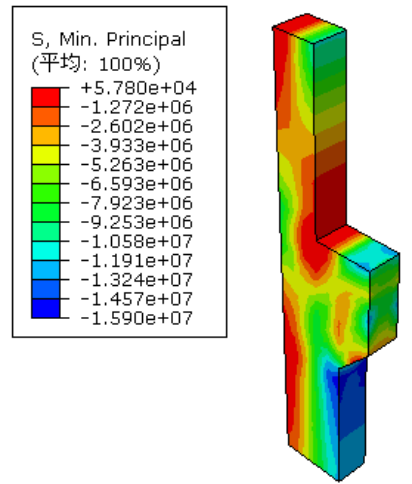
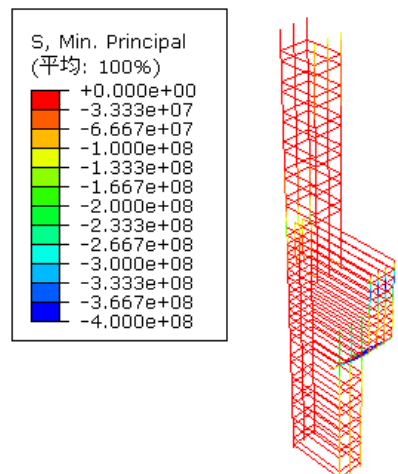

Fig-3 The third principal stress nephogram of rebar
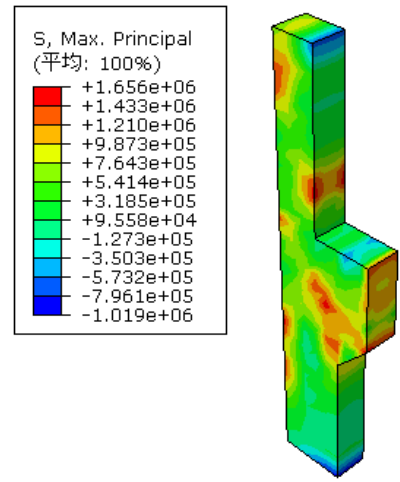

Fig-5 The first principal stress nephogram of deep corbel

Fig-6 The third principal stress nephogram of deep corbel Fig-7 Compression damage nephogram of deep corbel

Analysis of horizontal ultimate bearing capacity under the restriction of prestressing. Through the above analysis we can see that, the horizontal load makes a great effect on the bearing capacity of deep corbel. In order to improve the deep bracket horizontal ultimate bearing capacity and now uses the form of external prestressing. Previously calculated the horizontal ultimate bearing capacity is $50.471 \mathrm{kN}$ when the deep corbel is under the local pressure of $20 \mathrm{MPa}$. The first crack is located in the intersection of upper part and the platform. In order to make the confined area of the concrete better, so the tension control stress of $50 \mathrm{kN}$ is made by cooling method. The steel plates are anchored on the upper part of the platform, as shown in Figure 8.

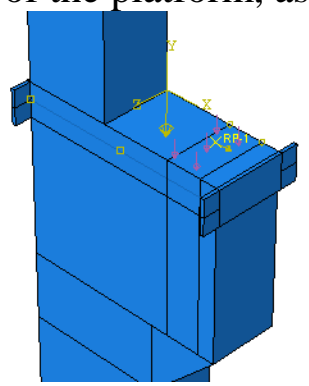

Fig-8 prestress location map of corbel 
The calculation results are shown in the following figure. When the horizontal load is applied to the $216.59 \mathrm{kN}$, the deep corbel is destroyed.Compared with the normal working state, the horizontal ultimate bearing capacity has been improved by 4.29 times.

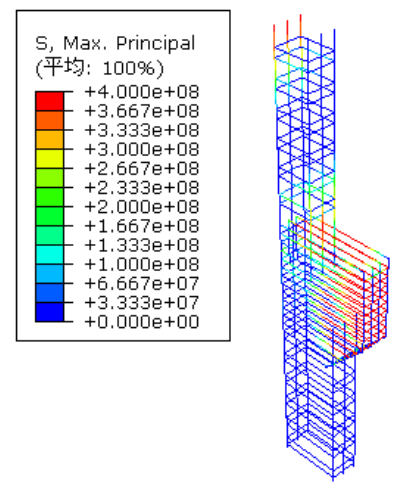

Fig-9 The first principal stress nephogram of rebar (prestress) of rebar (prestress)
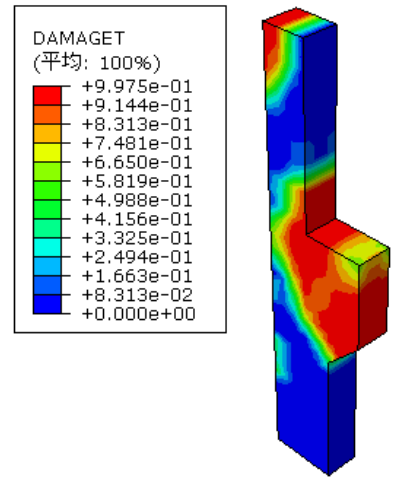

Fig-11 Tensile damage nephogram of deep corbel (prestress) of deep corbel (prestress)
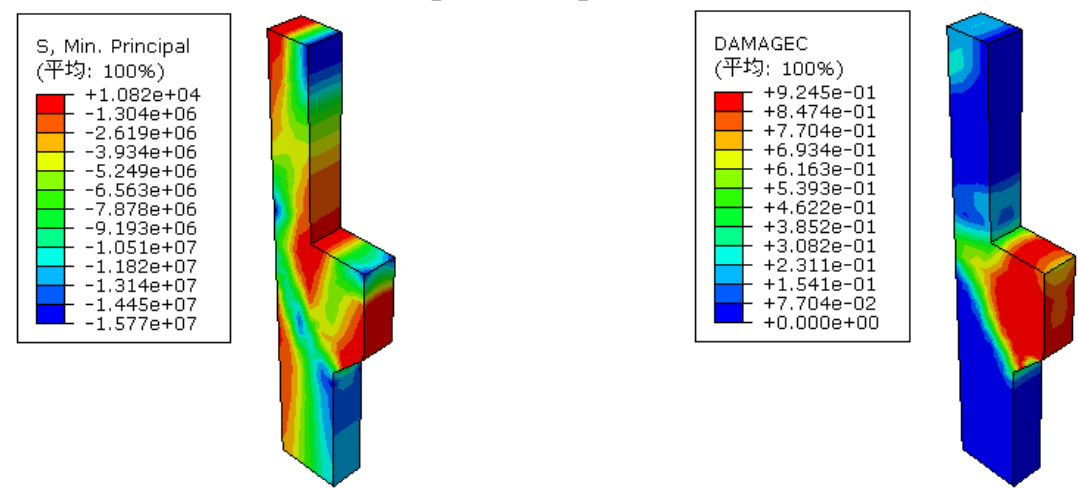

Fig-13 The third principal stress nephogram of deep corbel(prestress) Fig-14 Compression damage nephogram of deep corbel(prestress)

Combined with figure 9 and Figure 11, it can be seen that the cracking position is still located at the intersection of the upper column and the platform, and the position of the crack is consistent with the normal work. Due to prestressed steel strand counteract off a portion of the horizontal load, the horizontal ultimate bearing capacity of deep corbel increases, so we can see in Figure 11 , the concrete in central area of the deep corbel are tensile damaged. With the loss of prestressing and the increasing of horizontal load during the loading process, concrete in intersection of platform and upper column was one of the first to crack, then the crack quickly spread along the diagonal, eventually running through the whole extended area, makes the deep corbel is shear failure. Through Figure 9 and Figure 12, it can be seen that the reinforced area of tensile yield is greater than the area without prestress. The "tensile stress zone" in central region of corbel deep disappear, which shows that prestressed constraints can well improve the stress state of the central region of the corbel, make more rebar participate in the work before the failure, and then improve horizontal ultimate bearing capacity of the deep corbel. Through Figure 10 and Figure 13, it can be 
seen that the prestressing strand did not change the transfer path of the local pressure load, and the "compressive stress zone" still exists and has not changed. The maximum compressive stress in concrete is still located in the intersection of lower column and the inclined plane of extended area. Due to concrete in the central part of deep corbel under the action of prestressed steel strand, the stress state is changed from the original one-way pressure to two-way compression, So as to improve the bearing capacity. With the load increasing, see from Figure 14, the concrete in overhanging region of deep corbel is damaged at the right side of the cracking surface.

Horizontal ultimate bearing capacity under different conditions. Through the above analysis we can see, the horizontal ultimate bearing capacity of deep corbel is improved obviously by prestressed steel strand, which can effectively improve the stress state of concrete and rebar in the extended region. In order to further explore the relationship between vertical local load and horizontal ultimate bearing capacity during the deep corbel constrained by prestressing, apply vertical load of the different size and then obtain the horizontal ultimate bearing capacity of the deep corbel in constraint of non-prestressed and prestressed, as shown in Table 2.

Tab.2 $\quad$ Form of horizontal ultimate bearing capacity

\begin{tabular}{cccc}
\hline Serial number & Vertical load $(\mathrm{kN})$ & $\begin{array}{c}\text { Non prestressed } \\
\text { constraint }(\mathrm{kN})\end{array}$ & $\begin{array}{c}\text { Prestressed restraint } \\
(\mathrm{kN})\end{array}$ \\
\hline 1 & 200 & 487.236 & 869.293 \\
\hline 2 & 400 & 465.734 & 795.602 \\
\hline 3 & 600 & 445.689 & 757.583 \\
\hline 4 & 800 & 420.701 & 700.881 \\
\hline 5 & 1000 & 381.184 & 660.015 \\
\hline 6 & 1200 & 347.306 & 510.347 \\
\hline 7 & 1400 & 160.505 & 376.216 \\
\hline 8 & 1600 & 50.471 & 216.59 \\
\hline
\end{tabular}

As shown in Figure 15, the relationship between the vertical l load and the horizontal ultimate bearing capacity. From the graph, the horizontal ultimate bearing capacity decreases with the increasing of the vertical local load. When deep corbel is constrained by prestressing and vertical load is less than $1000 \mathrm{kN}$, the change of its horizontal ultimate bearing capacity is small. When the vertical load is greater than $1000 \mathrm{kN}$, the deep corbel bears large vertical load, the concrete of platform is strongly tensile by stress in the horizontal direction. The lateral loading makes the tensile stress of concrete further increase, finally accelerated the deep corbel failure. Therefore, when the vertical load is applied to the $1000 \mathrm{kN}$, the horizontal ultimate bearing capacity changes quickly. The same situation also occurs in the deep corbel during normal working condition, but the critical value of vertical load is $1200 \mathrm{kN}$.

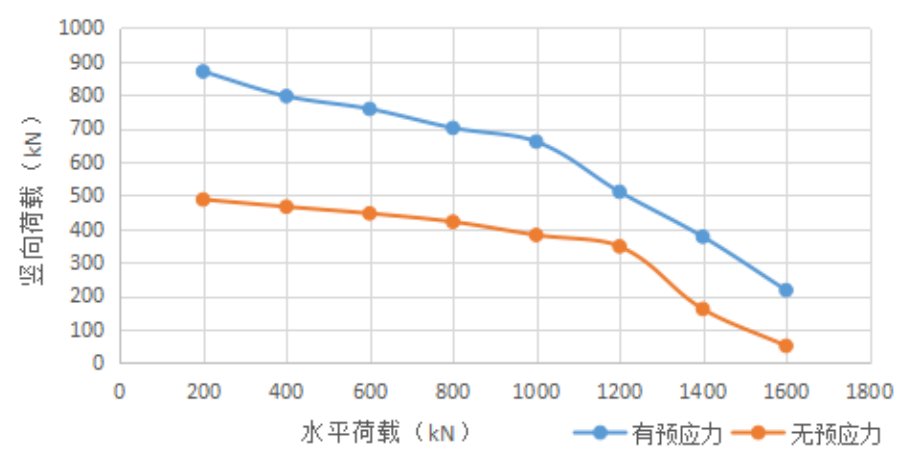

Fig-15 Relation diagram of the vertical local load and the horizontal ultimate bearing capacity

\section{Conclusion}

(1)The failure mode of deep corbel in the horizontal load is shear slip failure of intersection between platform and upper column, which is the same as the condition only vertical load works. 
(2)The horizontal ultimate bearing capacity is improved a lot with the restriction of the prestressed strand. The horizontal ultimate bearing capacity with prestressing is at least 1.47 times than that without prestressing , the effect is obvious.

(3)The horizontal ultimate bearing capacity decreases with the vertical load increasing when the deep corbel is under different vertical loads. When the vertical load is less than $1000 \mathrm{kN}$ during the deep corbel constrained by prestressing, the horizontal ultimate bearing capacity changes slower than the condition that the vertical load is more than $1000 \mathrm{kN}$. The critical value of the vertical load at the time of normal working is $1200 \mathrm{kN}$.

\section{Acknowledgements}

The selection of this thesis comes from the National Natural Science Foundation of China. The foundation number is 51178205.

\section{References}

[1] Peng Rong. Structure and calculation of bracket. Railway Survey and Design.2008 (4): 104-109 